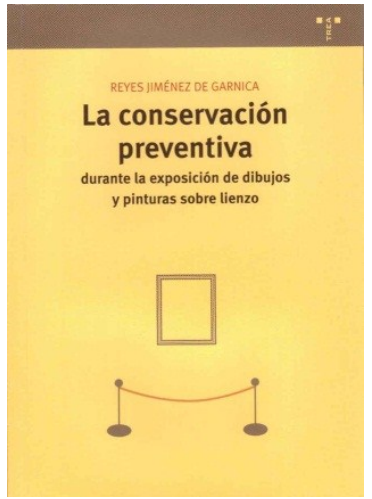

\title{
La conservación preventiva durante la exposición de dibujos y pinturas sobre lienzo
}

Reyes Jiménez de Garnica

Ediciones TREA, S.L.

Gijón (Asturias), 2011

95 páginas, ilustraciones en blanco y negro, y en color, 21 x $15 \mathrm{~cm}$.

ISBN: 978-84-9704-553-7

Hay que felicitar la iniciativa de Ediciones Trea de publicar en castellano una nueva colección de bolsillo titulada "Conservación y Restauración del Patrimonio", cuyo primer número aquí reseñamos. La serie, dirigida por Carme Bello y Àngels Borrell, se propone enfocar los más diversos aspectos de la conservación preventiva.

El lanzamiento de la colección se ha hecho con tres títulos: La conservación preventiva durante la exposición de dibujos y pinturas sobre lienzo, de Reyes Jiménez de Garnica; La conservación preventiva durante la exposición de esculturas en piedra, de Sonia Tortajada Hernando; y La climatización de los depósitos de archivos, bibliotecas y museos como método de conservación, de Zoel Forníes Matías. Además de éstos, se anuncian otras publicaciones igualmente sugerentes, a cargo tanto de profesionales consagrados como de una nueva generación de conservadores-restauradores que cuentan con una valiosa experiencia en sus respectivas trayectorias. Se trata de una colección práctica destinada a ofrecer una información sistematizada de fácil consulta.

Reyes Jiménez de Garnica tiene en su haber una amplia trayectoria en este campo y trabaja actualmente como responsable de conservación preventiva y restauración del Museu Picasso de Barcelona. Entre otras aportaciones a congresos y publicaciones debe destacarse por su novedad el reciente artículo "Una visión técnica del proceso de trabajo de Picasso", en Ciencia y Caridad al descubierto, que constituye el primer número de la Colección Focus editada por el Museo.

En el índice de La conservación preventiva durante la exposición de dibujos y pinturas sobre lienzo la autora aborda de manera detallada numerosos aspectos con los que debe enfrentarse un conservador a la hora de montar una exposición.

El libro se encuentra dividido en tres partes. La primera, más genérica, está dedicada a aspectos básicos de la conservación preventiva. En la segunda se aplica la conservación preventiva a la presentación de dibujos, mientras que la tercera se centra en las pinturas sobre lienzo.

La subdivisión del texto en numerosos epígrafes, junto con los cuadros resumen explicativos, los esquemas y dibujos, y algunos casos prácticos destacados, hacen que la publicación sea realmente útil, además de mostrar la capacidad de síntesis de la autora al desarrollar una cuestión tan amplia.

En el primer capítulo se analizan los problemas entre exponer y preservar las colecciones, la importancia del proyecto expositivo, el papel del conservador-restaurador, las características del espacio y de los elementos expositivos, así como las cuestiones de la iluminación, el medio ambiente y la seguridad.

La parte dedicada a la conservación preventiva en la presentación de dibujos es, quizás, la de mayor interés. En ella, después de explicar brevemente las técnicas y materiales propios de estas obras y sus procesos de deterioro, se detiene en el examen y preparación de los dibujos para su exhibición, en los procesos de montaje y sujeción, sistemas de presentación, enmarcado y almacenamiento. 
El capítulo dedicado a la conservación preventiva durante la exposición de pinturas sobre lienzo, se inicia también con algunas descripciones técnicas para pasar a las causas de alteración, a la documentación y preparación de la obra para su exhibición, el montaje y enmarcado, señalando ejemplos específicos de casos de pequeño y gran formato, y la relevancia de los diferentes tipos de marco.

El libro termina con unos anexos sobre materiales de protección, montaje y enmarcado, un modelo de ficha básica para exposiciones de dibujo y pintura, y una bibliografía específica sobre la cuestión tratada.

Entre otros aspectos destacables de la publicación, cabría señalar las acertadas reflexiones sobre errores del pasado que hoy se pueden evitar, como por ejemplo la referencia a las pinturas sobre lienzo que nunca fueron concebidas con bastidor. Las consecuencias de dichas faltas en los dibujos y en las pinturas se resumen por medio de interesantes cuadros sinópticos en las páginas 58 y 90.

Se puede asegurar que recibirán la mejor acogida y será de una gran utilidad en el ámbito de la conservación preventiva el contar con unos manuales que faciliten en pocas páginas la información indispensable para las diversas tareas de esta especialidad.

Ana Calvo

Universidad Complutense de Madrid

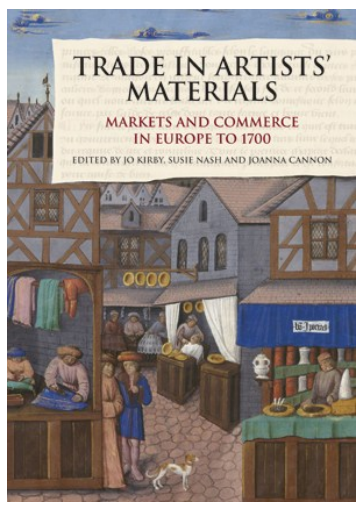

\section{Trade in Artists' Materials. Markets and Commerce in Europe to 1700 .}

Edited by Jo Kirby, Susie Nash y Joanna Cannon

Archetype Publications Ltd.

Londres, 2010

509 páginas, ilustraciones en color y blanco y negro, 297 x $210 \mathrm{~mm}$., pasta dura

ISBN: 978-1-904982-25-8

Esta publicación recoge las conferencias presentadas en la reunión internacional European Trade in Painters' Materials to 1700 que tuvo lugar en Londres en febrero de 2005, en el Courtauld Institute y en la National Gallery, bajo el patrocinio del International Academic Projects y el Courtauld Institute of Art. Además de las citadas conferencias, se han sumado otras contribuciones de interés sobre el mismo asunto. Así pues, se abordan en este libro el comercio de materiales, cuestiones de terminología y nuevas pruebas para la identificación de ciertos productos del mercado artístico, en el periodo entre $1200 \mathrm{y}$ 1700. Se presenta esta publicación en una cuidada edición en pasta dura, con magníficas ilustraciones en color y a toda página.

El libro constituye un homenaje a Caroline Villers (1948-2004) -entonces Directora del Departamento de Conservación y Tecnología del Courtauld Institute-, a la que David Bomford y Jørgen Wadum le dedican unas emocionadas palabras, al inicio del mismo, por su implicación en la organización de la conferencia sobre el mercado de los materiales artísticos. A continuación del prefacio de las editoras -Jo Kirby, Susie Nash y Joanna Cannon-, figura un artículo introductorio de Catherine Reynolds que resume 